\title{
Kung fu do exílio: os poemas de Ten Phun
}

\author{
Marina Della Valle
}

Resumo: $\mathrm{O}$ artigo apresenta uma breve análise e traduções para o português de três poemas do tibetano Ten Phun, publicados originalmente em inglês no livro Sweet Butter Tea.

Palavras-chave: Ten Phun; refugiado; língua e deslocamento, ativismo político

Abstract: The article presents a brief analysis and translations to Portuguese of three poems by Tibetan poet Ten Phun, published originally in English in his book Sweet Butter Tea.

Keywords: Ten Phun; refugee; language and dislocation; political activism 


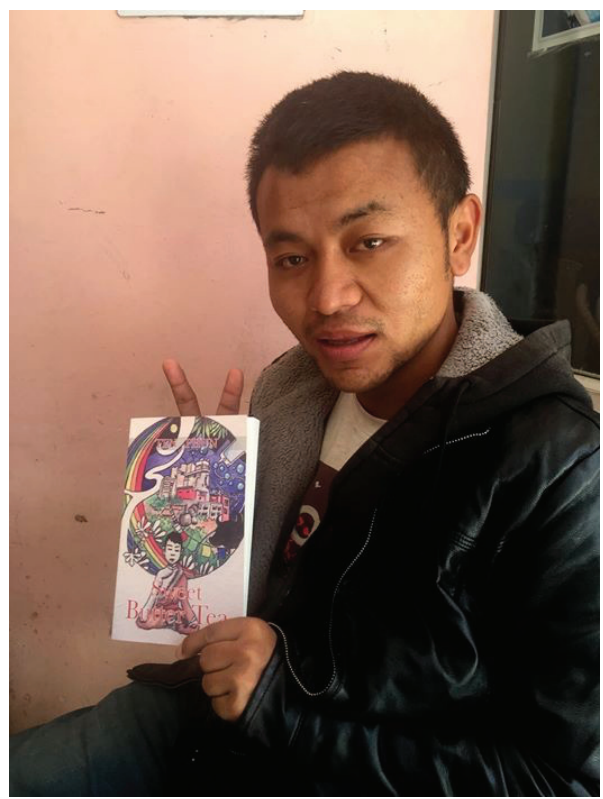

O exílio é o tema eternamente renovado na literatura, na medida em que parece eternamente presente na experiência humana - e basta uma olhada nas notícias do dia para perceber que o deslocamento de pessoas segue entre as principais questões da atualidade. E segue inspirando jovens poetas como Ten Phun, um dos nomes mais recentes da literatura em exilio tibetana em inglês.

Nascido em Lhasa, em 1988, Ten Phun perdeu os pais ainda criança e foi enviado para o mosteiro budista na mesma cidade. Em 1999, fugiu para a Índia, onde estudou em uma escola para refugiados tibetanos, depois passando um breve período na Universidade de Delhi, de onde saiu para viver em Dharamsala, sede do governo em exílio do $14^{\circ}$ dalai-lama, Tenzin Gyatso. Seu primeiro livro, Sweet Butter Tea, foi publicado em 2015 pelo selo Blackneck Books, ligado ao site Tibet Writes (www.tibetwrites.in), e em 2018 pela Square One, sendo vendido por plataformas online como a Amazon. Ten Phun também é rapper e atua no único grupo de teatro tibetano em exílio.

O uso do inglês entre os exilados tibetanos cresceu com a adoção do idioma nas escolas em 1960. Na Índia, as escolas tibetanas adotaram o modelo tibetano e o inglês como idioma principal (Bhoil, 2014). Ten Phun diz ter escrito em inglês para que sua mensagem pudesse atingir um público maior (Rosenbluth, 2015). O 
próprio uso do idioma sinaliza duas características dessa poesia: ativismo político (a perspectiva de atingir um público internacional, a menção a um Tibete livre) e o deslocamento, presente no uso de uma língua que não é a materna, a da terra natal perdida.

Mas vamos a uma breve análise dos três poemas escolhidos para a tradução, "Exile Kungfu", "Reminiscence", e "I Only Know". Os três trazem uma linguagem simples, coloquial. Diferentes elementos reforçam a ideia de oralidade. Em "Exile Kungfu", a estrutura de perguntas sugere diálogo; em "Reminiscence", há um movimento de expansão e retração dos versos, sugerindo a cadência de alguém que conta uma história; já "I Only Know” é estruturado sobre repetições da fórmula "I don't know/I only know". Ten Phun usa versos livres, sem esquemas fixos de rimas.

De modo geral, a experiência de leitura é melancólica; a experiência de perda e deslocamento é desenhada em alusões a coisas cotidianas, corriqueiras, como em "Reminiscence", que descreve Lhasa para evocar "the Neverland of my childhood", a "Terra do Nunca de minha infância". Em "Kungfu", a memória da cidade natal é contraposta com a repetição de exílio como adjetivo: fantasias, lágrimas, memórias, sapatos, são todos "de exílio"; as alternativas para expressar suas "experiências aqui" incluem expressar agradecimento à Índia ou perdão à China em contraposição a aguentar a reclamação da dona da casa - ou voltar. Em "I Only Know", entre as incertezas estão se o poeta verá de novo sua terra natal, ou se o Tibete será livre; entre as certezas, a de que sentem sua falta. Em seu texto introdutório, o poeta anuncia essa atmosfera melancólica: "Most of my poems reflect the myriad tunes of loneliness and sadness and the poignancy of our lives in exile" (A maior parte de meus poemas reflete a miríade de canções de solidão e tristeza e a pungência de nossas vidas no exílio).

As propostas de tradução apresentadas a seguir foram feitas partindo da ideia de tradução poética de Haroldo de Campos: "Na tradução de um poema, o ideal não é a reconstituição da mensagem, mas a reconstituição do sistema de signos em que está incorporada essa mensagem, da informação estética, e não meramente semântica" (CAMPOS, 1969, p. 100). Ou seja, com atenção para a recriação de elementos semânticos e estéticos: padrões rítmicos e métricos, esquemas de rimas, efeitos aliterativos etc. Isso não significa que a semântica foi deixada de lado, mas que as traduções apresentadas aqui buscaram identificar e reproduzir, na medida do possível, os processos de organização do poema, seus padrões sonoros, gráficos e também sintáticos/semânticos. Como coloca Mario Laranjeira, “a 'gramática' do poema, os jogos de equivalências fônicas, sintáticas, semânticas, 
de cujos acoplamentos se origina a estrutura poética atualizada naquele poema e não noutro" (LARANJEIRA, 1993, p. 62), ou seja, a combinação de elementos que individualiza aquela obra.

De modo geral, as traduções aqui apresentadas tentaram manter o número de tônicas em cada verso, assim como equivalências para os padrões sonoros, no habitual jogo de perdas e compensações envolvido na tradução poética - não considerei proveitoso incluir aqui as esquematizações desta parte do trabalho, preferindo comentar questões pontuais.

No caso de "Exile Kungfu", manteve-se a repetição da estrutura "should I count" ("devo eu contar") e da palavra "exile" como adjetivação ("de exílio") na primeira estrofe. A introdução do "eu" em "devo eu contar", colocando uma sílaba a mais em um verso que poderia ser mais enxuto, foi motivada pela tentativa de mimetizar o ritmo da expressão original. Apesar da tentativa geral de manter a linguagem simples do original, "landlady" foi traduzida como "senhoria", em vez de um mais corriqueiro "dona da casa", para não diluir a expressão de não pertencimento, uma vez que o verso final termina "trek home", em oposição à moradia com teias de aranha no teto, por sua vez traduzido como "andar para casa".

"I only know" é estruturado em torno da repetição do início dos versos (I don't know/I only know"), com estrofes de dois versos, um esquema simples, de fácil memorização, que evoca a palavra falada, o ato de declamar para uma plateia. Uma vez decidida a tradução deste padrão estruturante (Não sei/Só sei), o restante do poema não trouxe grandes dificuldades.

"Reminiscences" trouxe a questão de diferenças de grafia causadas pela transliteração de palavras com a constatação de uma diferença de grafia no nome do mercado no corpo do poema (Tomsing Khang) e na nota explicativa (Tomsig Khang). Uma busca no Google a partir do Brasil não registrou nenhuma das grafias, de modo geral, nas publicações ocidentais o nome do mercado é grafado como Tromsikhang. Adotar a grafia mais comum não pareceu uma solução adequada, uma vez que o poeta fez outra escolha, talvez realçando o elemento estrangeiro do nome em um poema em inglês; consultado por meio de mensagem, Ten Phun indicou a grafia correta (Tomsig Khang). Neste poema, duas características foram tomadas como guia na tradução: o movimento de expansão e retração dos versos, que sugere alguém que divaga, a própria reminiscência do título; e os nomes de locais de Lhasa e do nome do mastim, indicadores da identidade da terra perdida. Os efeitos pretendidos na tradução foram a recriação desse movimento gerado 
pelo aumento e diminuição do tamanho e da duração dos versos, assim como incorporar os nomes em tibetano como ponto de partida para a recriação dos padrões fônicos do poema.

\section{Exile Kungfu}

To tell you how much I miss my hometown, should I count my exile fantasies and my exile tears? should I count my exile memories and my exile shoes?

To explain my experiences here, should I sing a song of "Thank you India" or share my message of forgiveness to China? Should I bear the complaints of my landlady, and sigh at the grimaces of this cobweb-ceilinged room? Or should I lace my hiking boots and trek home?

\section{Kung fu do exílio}

Pra lhe dizer o quanto sinto falta de minha cidade devo eu contar minhas fantasias de exílio e meu pranto de exílio? devo eu contar minhas memórias de exílio e meus sapatos de exílio?

Pra explicar minhas experiências aqui devo cantar uma canção de "Grato, Índia" ou mostrar minha mensagem de perdão à China? Devo aguentar as queixas da senhoria, e suspirar para as caretas no teto de teias de aranha? Ou devo amarrar as botas de caminhar e andar para casa? 


\section{I only know}

I don't know if I will ever see my homeland, I only know someone there misses me.

I don't know how old my heart is, I only know my five o'clock shadow tells it all.

I don't know how to write a constructive poem, I only know how to pour feelings into words.

I don't know complicated philosophies, I only know salt is salty and sugar is sweet.

I don't know what the future might hold for me, I only know I am still breathing.

I don't know how foolish I am, I only know I am very stubborn.

I don't know if fate exists or not, I only know hurting someone's feelings is wrong.

I don't know whether failure is a part of life, I only know how to digest it and move on.

I don't know how each second passes, I only know we all become old.

I don't know when Tibet will be free, I only know the birds in the sky fly free. 


\section{Só sei}

Não sei se verei um dia minha terra natal,

Só sei que alguém lá sente minha falta.

Não sei a idade de meu coração,

Só sei que a sombra da minha barba diz tudo.

Não sei escrever um poema construtivo,

Só sei derramar sentimento em palavras.

Não sei filosofias complicadas,

Só sei que sal é salgado e açúcar é doce.

Não sei o que o futuro pode me trazer,

Só sei que ainda respiro.

Não sei o quanto sou tolo,

Só sei que sou muito teimoso.

Não sei se existe destino,

Só sei que é errado ferir os sentimentos de alguém.

Não sei se o fracasso é parte da vida

Só sei digeri-lo e seguir adiante.

Não sei como se passa cada segundo,

Só sei que todos envelhecemos.

Não sei quando o Tibete será livre,

Só sei que os pássaros voam livres no céu. 


\section{Reminiscence}

In my dreams I relive my boyhood days running a kite along the narrow streets of Lhasa sailing the paper boat on a river nearby our house peeking into a small CD shop at the corner of Tomsig Khang* and imagining owning one while reaching adulthood.

For two yuan of noodles I would spend days

watching Tibetan movies in a restaurant inside Bharkor*.

Those memories are enshrined in me.

The pulse of it makes me ponder

the Neverland of my childhood, the dire times of lonesome living with Wangdue our mastiff, my little sheep and all my toys under the cool light of the moon.

I would wait to see Tara with her rabbit high up in the sky, I would wish for a divine sage, drifting on clouds.

*Tomsig Khang is a popular market in Lhasa.

*Bharkor is an ancient street surrounding the Jokhang Temple in Lhasa where Tibetans perform koras or circumambulations. 


\section{Reminiscência}

Nos sonhos revivo meus dias de menino

empinando pipa nas ruas estreitas de Lhasa

navegando barcos de papel no rio perto de casa

espiando uma lojinha de CDs na esquina do Tomsig Khang a imaginar

ser dono de uma quando fosse adulto.

Por dois iuanes de macarrão passava dias

vendo filmes tibetanos num restaurante

em Bharkor.

Essas memórias estão resguardadas em mim.

Seu pulso me faz pensar

na Terra do Nunca da minha infância,

nos tempos difíceis de vida solitária com Wangdue,

nosso mastim,

minhas ovelhinhas e todos os meus brinquedos

sob a luz fria da lua.

Esperava para ver Tara e seu coelho

no alto do céu,

desejava um sábio divino, pairando nas nuvens.

*Tomsig Khang é um mercado popular em Lhasa.

*Bharkor é uma rua antiga em torno do templo Jokhang, em Lhasa, na qual os tibetanos fazem os koras, ou circunvoluções. 


\section{Referências bibliográficas}

BHOIL, Shelly. A brief survey. In Muse India, 57. Disponível em: < http:/ / www.museindia. $\mathrm{com} /$ Home $/$ ViewContentData? arttype $=$ feature\&issid $=57 \&$ menuid $=5139>$. Acesso em .. CAMPOS, Haroldo de. "A palavra vermelha de Holderlin”. In $A$ arte no horizonte do provável e outros ensaios. Ed. Perspectiva. São Paulo, 1969. Pp. 100.

LARANJEIRA, Mário. Poética da tradução: do sentido à significância. São Paulo: Edusp, 1993. PHUN TEN, Sweet butter tea. Square One, 64 p., 2018

ROSENBLUTH, Imogen. Too many rented rooms: creative expression in the Tibetan community and the foreign artist. Independent Study Project (ISP) Collection. 2227. (2015) Disponível em: < https://digitalcollections.sit.edu/isp collection/2227>.

Marina Della Valle é doutora em Estudos Linguísticos e Literários em Inglês, Departamento de Letras Modernas, FFLCH, USP, com pesquisa na Universidade de Cambridge. Graduada em Jornalismo pela Faculdade Casper Líbero (1997). Membro da comissão editorial da revista Cadernos de Literatura em Tradução (Humanitas-USP), ligada ao Departamento de Letras Modernas da FFLCH-USP. Áreas de atuação: Estudos da Tradução, tradução poética. 